\title{
Rhythms in the Biting Behaviour of a Mosquito Armigeres subalbatus
}

\author{
R. Selvaraj Pandian and M.K. Chandrashekaran \\ Unit of Animal Behaviour, School of Biological Sciences, Madurai Kamaraj University, Madurai-625021 India
}

\begin{abstract}
Summary. The biting cycle of Armigeres subalbatus is distinctly crepuscular, exhibiting two peaks of activity, a smaller one at dawn and a larger one at dusk. The biting cycle is entrained to natural light-dark cycles and the time interval from dawn to dawn or dusk to dusk peaks is exactly $24 \mathrm{~h}$ and from dawn to dusk or dusk to dawn is about $12 \mathrm{~h}$ measured at $50 \%$ level. This rhythm manifests itself day after day without any marked qualitative change.

The rate of change of light intensity may determine the onset of crepuscular biting. The sudden increase (up to ca. $17 \mathrm{~lx}$ ) or decrease (down to ca. $4 \mathrm{~lx}$ ) in the intensity of ambient light at the time of sunrise or sunset coincides with the peak of the biting activity.

The density of the population of the host-seeking females fluctuates in relation to the phases of the moon, increasing with the full moon phase and decreasing with the new moon phase.

Even though the density of the population is greater outdoors than indoors both at ground level and in the first floor, the peak of activity occurs at the same time in all the places. A vertical stratification of biting activity was also noticed.
\end{abstract}

\section{Introduction}

Clements (1963) states that most species of mosquitoes bite for a restricted period during the $24 \mathrm{~h}$ cycle and those species which are active throughout this cycle bite most readily during one or two limited periods. Haddow (1954) suggests that the different types of biting behaviour fall into two main classes:

i) that in which there is a single, very short and very pronounced wave of biting activity, although there is always scattered biting at other times;

ii) that in which biting activity goes on over a prolonged period.

The latter type is strikingly irregular apart from being either diurnal or nocturnal or crepuscular. Studies have been made on the biting activity rhythms in Aedes aegypti (Teesdale 1955; McClelland 1959; Boorman 1960; Trpis et al. 1973 and 1974), Aedes simpsoni (Lumsden 1955; Gillett 1969), Aedes polynesiensis and Aedes pseudoscutellaris (Rakai 1974), in Culex vishuni, $C$. pseudovishuni, C. tritaeniorhynchus, C. bitaeniorhynchus, Anopheles hyrcanus, An. pallidus, An. subpictus (Reuben 1971), Culiseta inornata (Barnard 1977), An. gambiae, An. zcemanni, An. funestus and An. pharoensis (Chandler 1975, 1976; Krafsur 1977).

Practically no information, however, is available on the fine structure of the biting cycles especially with reference to triggering, regulatory and modifying environmental factors. The studies conducted on Armigeres subalbatus and reported here seek to investigate:

1. the periodicity of the biting cycle

i) within the day-night cycle and

ii) from day to day

2. the nature and persistence of the biting cycle

3. the effect of ambient light intensity on the biting cycle,

4. the fluctuation of the density of the population of hostseeking females in relation to the phases of moon and

5. to identify the type of biting behaviour.

\section{Materials and Methods}

The tribe Aedini consists of three genera namely Armigeres, Aedes and Heizmannia. In the present study, Armigeres subalbatus has been selected. A. subalbatus is a large species occurring throughout the year but found in abundance from November to March in Madurai. It breeds in foul smelling and stagnant water. Swarming behaviour has been observed in this species prior to the peak of biting activity. The female mosquitoes feed on the blood of human beings and also on that of other vertebrates, whereas the males exhibit nectar-feeding activity. Ingestion of a minimum amount of blood is necessary to initiate the development of eggs as in other species of mosquitoes. The females take one blood meal or more per gonotrophic cycle or before developing each batch of eggs. The time of feeding activity is presumably controlled by a circadian (or photoperiod) "clock" but the level of illumination during twilight hours affects the initiation, duration and cessation of feeding.

The collection site is located in Nagamalai Pudukottai which is $9 \mathrm{~km}$ from Madurai and located in between Nagamalai and Samanamalai hills (Latitude $9^{\circ} 58^{\prime} \mathrm{N}$; Longitude $78^{\circ} 10^{\prime} \mathrm{E}$ ). This site provides suitable breeding and roosting sites for the mosquitoes to occur in larger numbers. Collections were made while the mosquitoes were biting in a house in the first floor (open terraced), visiting hall, study room, northern and southern sides of the house and in the backyard garden.

As the female mosquitoes readily bite humans, legs below the knee of the investigator were exposed to be bitten. Mosquitoes alighting on the legs were collected with a transparent plastic vial $\left(5^{1} / 2 \mathrm{~cm} \times 2 \mathrm{~cm}\right)$ continuously for $24 \mathrm{~h}$. The catch was separated according to hours, identified and recorded. A red light source of $610 \mathrm{~nm}$ was used for illumination during dark periods.

The collections were made for $24 \mathrm{~h}$ in the spots mentioned earlier to predict the nature of the biting cycle. The collections were made between $0530 \mathrm{~h}$ and $1930 \mathrm{~h}$ indoors, outdoors and in the first floor to identify the biting behaviour. The collection site located in the southern side of the house, was used to study the effect of moon light, twilight and the timings of sunset and sunrise on the biting activity rhythm of these mosquitoes and the collections were made between $05.30 \mathrm{~h}$ and $07.30 \mathrm{~h}, 17.30 \mathrm{~h}$ and $19.30 \mathrm{~h}$ (peak hours) for twenty days. The collections were carried out in February and March, 1979. 
Since A. subalbatus is dawn and dusk active, the values of the midpoints of morning and evening peaks are correlated with those of sunrise and sunset. Sunrise and sunset times were obtained from the tables published by the Regional Meteorological Centre, Calcutta and were adjusted for longitude and latitude. The light intensities were measured during the morning and evening twilight with an optometer (UDT) by pointing the light receiving unit towards the horizon and keeping the apparatus at a fixed place very close to the collection site. The lowest level of light intensity that could be directly and reliably measured was $0.001 \mathrm{ft.c}$.

\section{Results}

Analysis of biting cycles shows that Armigeres subalbatus is distinctly crepuscular, exhibiting 2 peaks of activity a smaller peak at dawn and a relatively larger peak at dusk. Peaks of the biting cycle coinciding with dusk are invariably larger (Table 1 and Fig. 1).

Studies conducted to analyse the pattern and periodicity of the biting cycle show that the rhythm is apparently under a state of strict "entrainment" by the light-dark cycles of the environment, the time interval between the median of a dawn or dusk peak (22.2.1979) to the median of a corresponding peak on the next day (23.2.1979) is exactly $24 \mathrm{~h}$. The time interval between morning and evening peaks is about $12 \mathrm{~h}$ (Fig. 2). The biting activity rhythm manifests itself day after day without any marked qualitative changes (Fig. 3).

The peak of the biting activity is determined by a threshold intensity of ambient light at the time of sunrise or sunset. The median value of the morning peak falls at $06.28 \mathrm{~h}$ when the sunlight intensity is about $17 \mathrm{~lx}$ (Fig. 4a). The median value of the evening peak falls at $18.38 \mathrm{~h}$ when the sunlight intensity is about $4 \mathrm{~lx}$ (Fig. $4 \mathrm{~b}$ ). This shows that the rate of change of light intensity and not an absolute fixed level or value is the critical factor which determines the activity peak of crepuscular biting mosquitoes.

The field studies conducted for twenty consequent days from 22nd February 1979 to 3rd March 1979 and from 8th March 1979 to 17 th March 1979 reveal that the midpoint values of both morning and evening peaks and the time of sunrise and sunset respec-

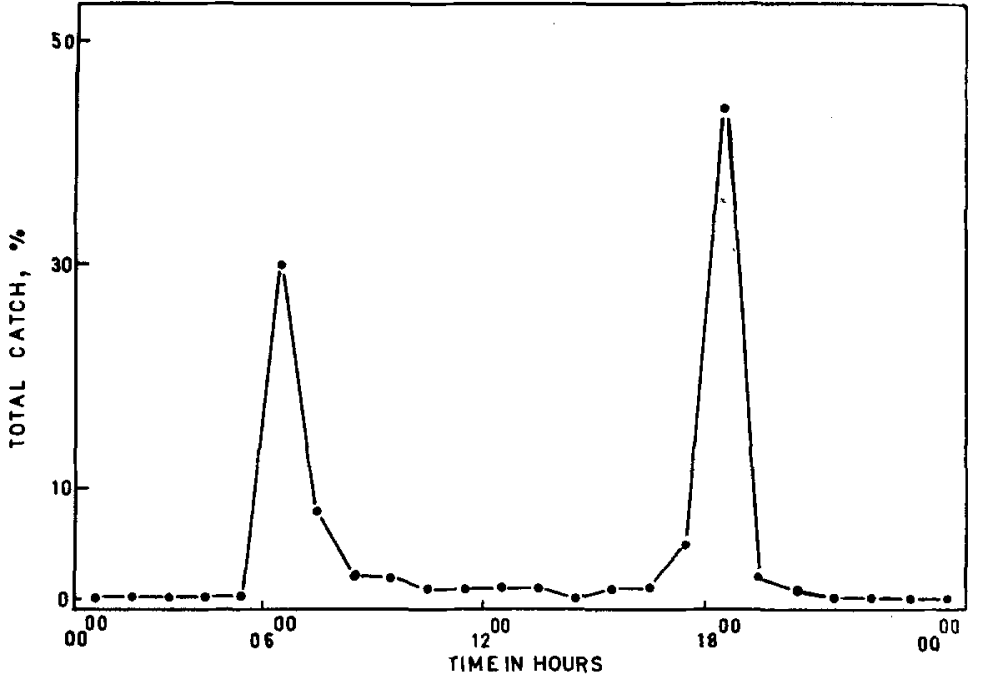

Fig. 1. The biting cycle of Armigeres subalbatus landing on man, expressed as percentage per hour of the total for $24 \mathrm{~h}$

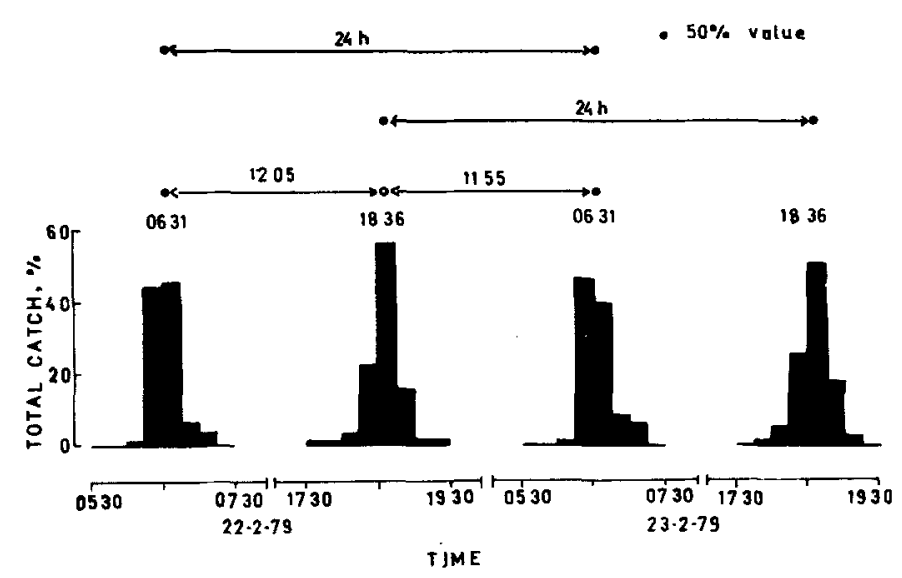

Fig. 2. The pattern and periodicity of the biting cycle of $A$. subalbatus within a day and from day to day

Table 1. The biting activity of Armigeres subalbatus according to one-hour grouping (Numbers of females of Armigeres subalbatus collected in five different sites at Plot No. 123, N.G.G.O's. Colony, Nagamalai)

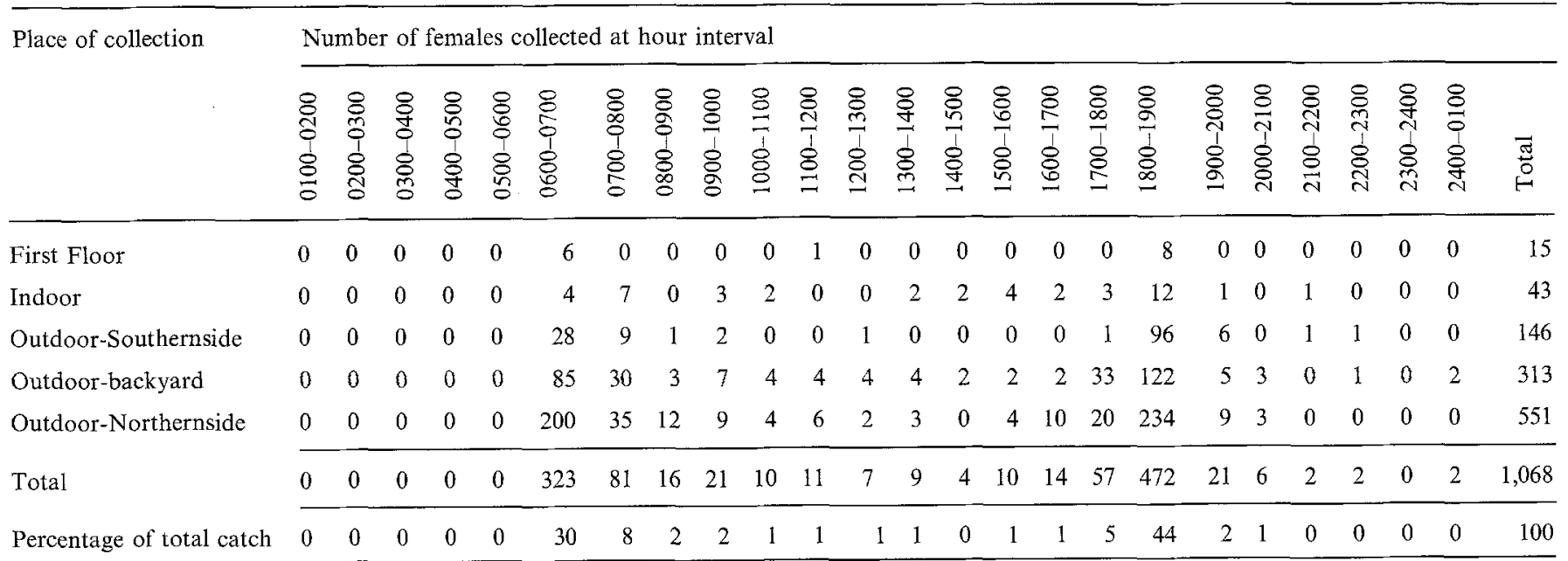




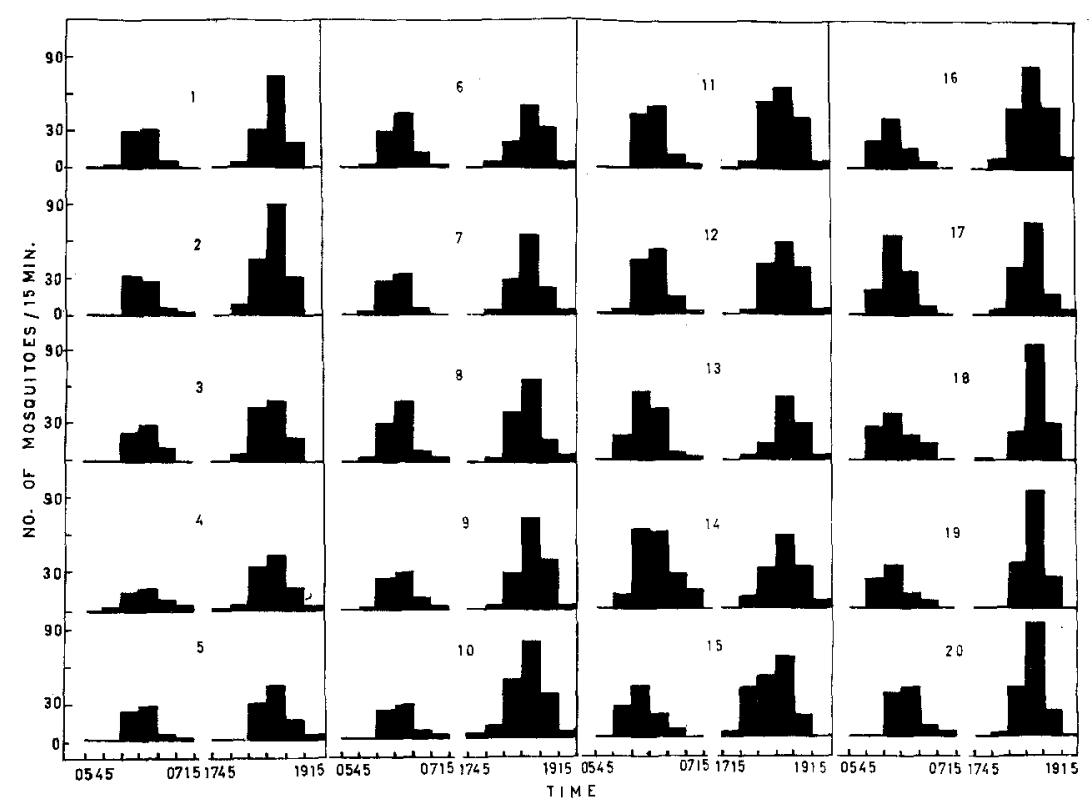

Fig. 3. The pattern of biting activity cycle exhibited by A. subalbatus. The collections were made between $05.30 \mathrm{~h}$ and $07.30 \mathrm{~h} \& 17.30$ and $19.30 \mathrm{~h}$ for twenty days. Number 1 to 20 indicate the dates of the collection. $1-10=22$ nd February to 3rd March, 1979. 11-20=8th March to 17th March, 1979
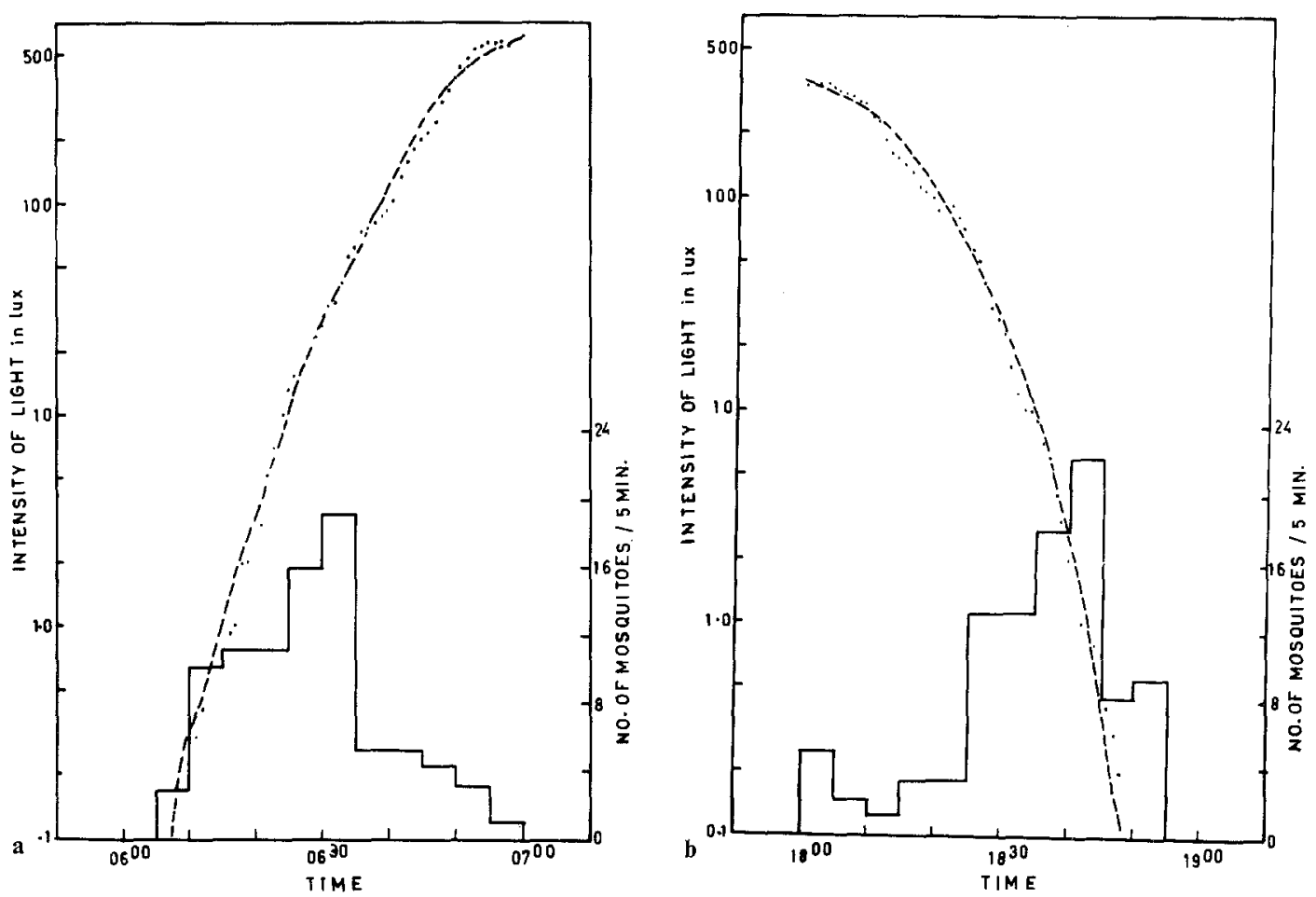

Fig. 4. a Relationship between the steep increase in the intensity of light at the time of sunrise and the morning peak of biting cycle of $A$. subalbatus. b Relationship between the drop in the intensity of light at the time of sunset and the evening peak of the biting cycle of $A$. subalbatus

tively coincide. The time of sunrise and the midpoint of the morning peak are congruent in time whereas the midpoint of evening peak occurs 8 to 9 min past sunset (Table 2 and 3 and Fig. 5).

Studies conducted to find out the influence of phases of moon reveal that the size of the catches increases with the waxing phase of the moon from a minimum at new moon (26.2.1979) to maximum at full moon (13.2.1979) (Fig. 6). The numbers of hostseeking female mosquitoes caught during the peak hours on full moon day (13.2.1979) and on new moon day (26.2.1979) indicate that peaks coinciding with moonlit nights tend to show higher values.

The total number of mosquitoes caught in the garden, outdoors, indoors and in the first floor shows that $A$. subalbatus is active predominantly outdoors. But, the peak of activity is maintained at the same hour in all the sites where collections were made (Fig. 7). 
Table 2. Data on the time of sunrise and sunset and the $50 \%$ value of morning peaks and evening peaks calculated from 22.2.1979 to 3.3.1979 and from 8.3.1979 to 17.3.1979. 26.2.1979=New moon day; $13.3 .1979=$ Full moon day

\begin{tabular}{|c|c|c|c|c|}
\hline \multirow[t]{2}{*}{ Date } & \multicolumn{4}{|l|}{ Time of } \\
\hline & Sunrise ${ }^{a}$ & $\begin{array}{l}50 \% \text { value } \\
\text { of morning } \\
\text { peak }\end{array}$ & Sunset $^{\mathrm{a}}$ & $\begin{array}{l}50 \% \text { value } \\
\text { of evening } \\
\text { peak }\end{array}$ \\
\hline 22.2.1979 & & 06.31 & & 18.36 \\
\hline 23.2 .1979 & & 06.31 & & 18.36 \\
\hline 24.2 .1979 & & 06.36 & & 18.33 \\
\hline 25.2 .1979 & 06.33 & 06.36 & 18.27 & 18.34 \\
\hline 26.2 .1979 & & 06.34 & & 18.36 \\
\hline 27.2 .1979 & & 06.36 & & 18.40 \\
\hline 28.2 .1979 & & 06.33 & & 18.37 \\
\hline 1.3 .1979 & 06.32 & 06.34 & 18.28 & 18.36 \\
\hline 2.3.1979 & & 06.35 & & 18.39 \\
\hline 3.3.1979 & & 06.34 & & 18.39 \\
\hline 8.3 .1979 & & 06.33 & & 18.36 \\
\hline 9.3 .1979 & 06.28 & 06.33 & 18.29 & 18.37 \\
\hline 10.3 .1979 & & 06.27 & & 18.40 \\
\hline 11.3 .1979 & & 06.34 & & 18.37 \\
\hline 12.3 .1979 & & 06.23 & & 18.28 \\
\hline 13.3 .1979 & 06.26 & 06.22 & 18.28 & 18.41 \\
\hline 14.3 .1979 & & 06.25 & & 18.36 \\
\hline 15.3 .1979 & & 06.24 & & 18.38 \\
\hline 16.3 .1979 & & 06.22 & & 18.37 \\
\hline 17.3 .1979 & 06.23 & 06.33 & 18.28 & 18.33 \\
\hline
\end{tabular}

a Sunrise and sunset times were obtained from the tables published by the Regional Meteorological Centre, Calcutta and were adjusted for longitude and latitude

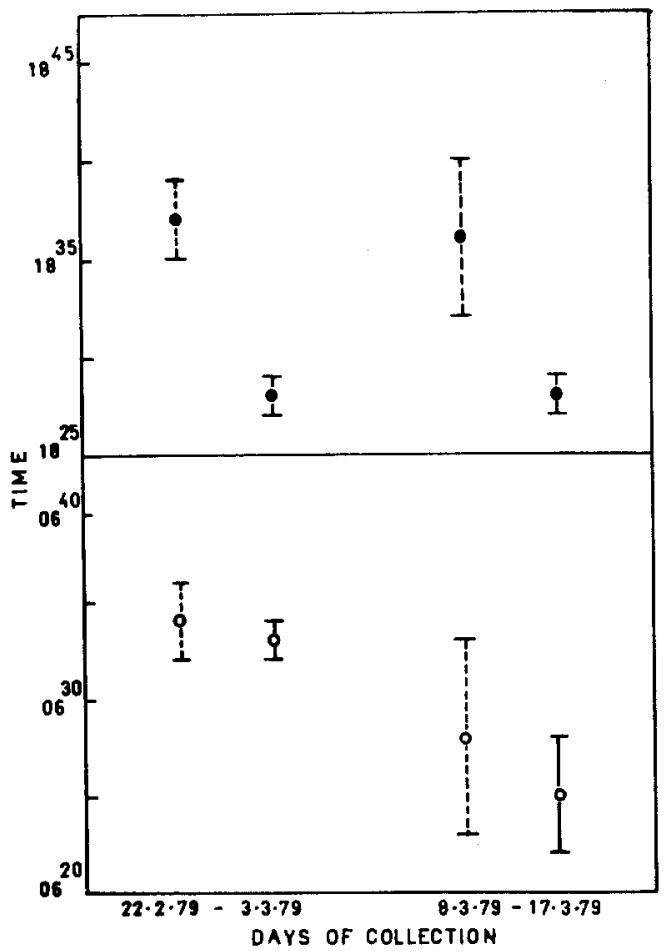

Fig. 5. Relationship of the time of sunrise and sunset to mid-point values of the peaks

Ordinate: Time in $\mathrm{h}$

Abscissa: averaged values for clusters of 10 days on timing of sunrise

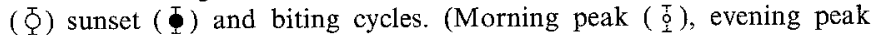
$\left(\begin{array}{l}0 \\ \hdashline\end{array}\right)$
Table 3. The mid-point values of the morning and evening peaks of the biting cycle of Armigeres subalbatus and the time of sunset and sunrise. Values represent the mean $\pm \mathrm{SE}$

\begin{tabular}{|c|c|c|}
\hline $\begin{array}{l}50 \% \text { value of the peak } \\
\text { (mid-point value) } \\
\text { in } \mathrm{h}\end{array}$ & $\begin{array}{l}\text { Sunrise/Sunset } \\
\text { in } \mathrm{h}\end{array}$ & Period \\
\hline \multicolumn{3}{|l|}{ Morning peak } \\
\hline $\begin{array}{l}0634 \pm 0.02 \\
0628 \pm 0.05\end{array}$ & $\begin{array}{l}0633 \pm 0.01 \\
0625 \pm 0.03\end{array}$ & $\begin{array}{r}22.2 .1979 \text { to } 3.3 .1979 \\
8.3 .1979 \text { to } 17.3 .1979\end{array}$ \\
\hline \multicolumn{3}{|l|}{ Evening peak } \\
\hline $\begin{array}{l}1837 \pm 0.02 \\
1836 \pm 0.04\end{array}$ & $\begin{array}{l}1828 \pm 0.01 \\
1828 \pm 0.01\end{array}$ & $\begin{array}{r}22.2 .1979 \text { to } 3.3 .1979 \\
8.3 .1979 \text { to } 17.3 .1979\end{array}$ \\
\hline
\end{tabular}

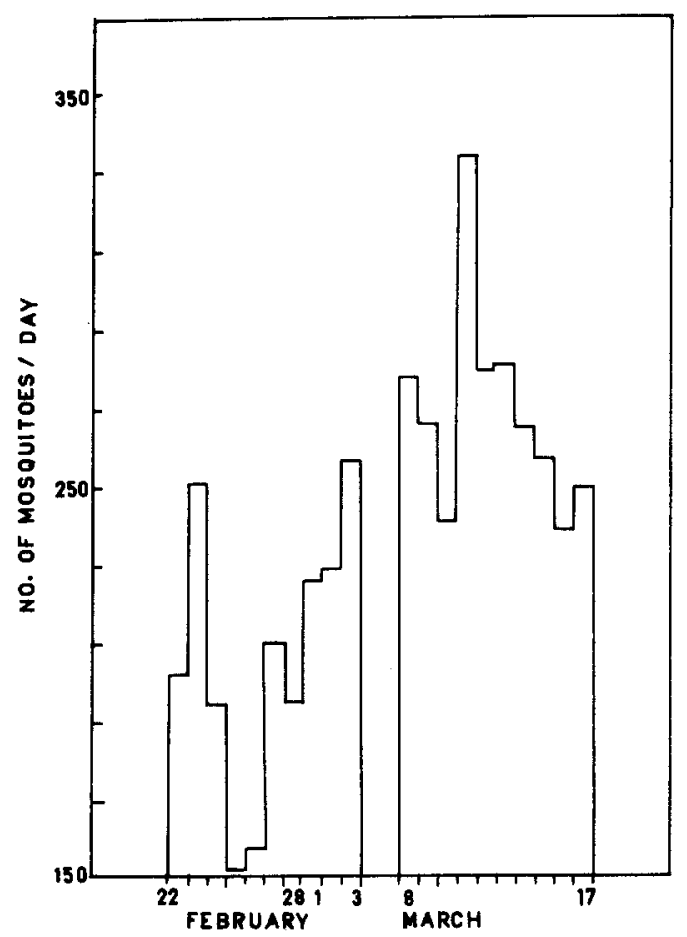

Fig. 6. Number of female mosquitoes caught per day from 22nd February to 3rd March and 8th March to 17th March, 1979

\section{Discussion}

\section{The Pattern of Biting Cycle}

The studies on the biting activity clearly confirm the predominantly crepuscular behaviour of Armigeres subalbatus. Peaks in landing and biting activity of females on man occurred at dawn and dusk and all catches have shown definite bimodality. The biting or landing of the mosquitoes outside the peak hours is very low. The amplitude of the evening peaks was higher than that of the morning peaks in all catches. This pattern exactly resembles the crepuscular biting pattern exhibited by Aedes tormintor and Aedes atlanticus as shown by Roberts et al. (1975). The bimodal biting cycle is also observed in the diurnal mosquitoes Aedes aegypti (Teesdale 1955; McClelland 1959; Boorman 1960; Trpis et al. $1973,1974)$ and the unimodal activity is reported in the nocturnal mosquitoes Culex spp. (Reuben 1971), Culiseta inornata (Barnard 


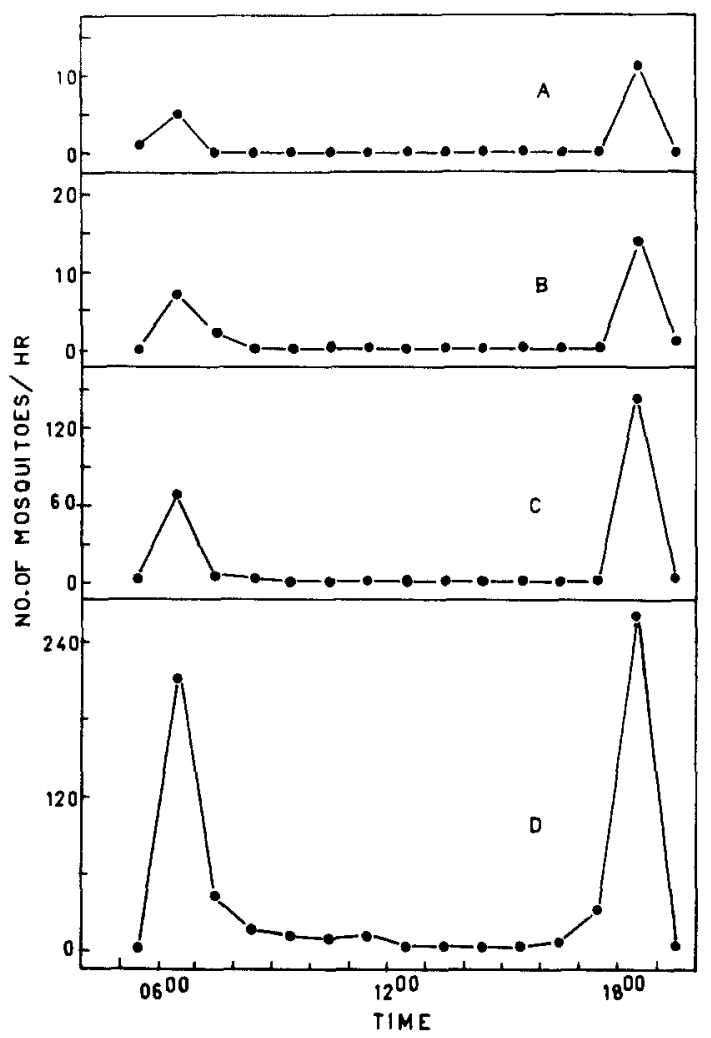

Fig. 7A-D. Numbers of female mosquitoes caught at 4 different sites indicating the biting cycle of $A$. subalbatus. A First floor (open terraced). B Study room (Indoor). C Southern side (Outdoor). D Garden (Outdoor). The peak of activity is maintained at the same hour in all the sites $(A-D)$

1977) and Anopheles spp. (Chandler 1975, 1976; Krafsur 1977). The common occurrence of cycles with the asymmetry in the peak of bimodal biting activity amplitude may be due to the sections of populations involved. Further, it is not clear whether both peaks are controlled by an endogenous factor or not.

\section{Entrainment of the Biting Cycle to Natural LD Cycle}

When an endogenous oscillator is subjected to environmental light cycle the period of the oscillator becomes the same as that of the Zeitgeber provided the latter is within the oscillator's range of entrainment. In natural light dark cycles the oscillator therefore adopts a period which is exactly that of the solar day, namely $24 \mathrm{~h}$ and is considered to be entrained (Saunders 1976). The biting cycle in Armigeres subalbatus is apparently under a state of strict 'entrainment' by the light-dark cycles of nature. An experimental approach to biting cycles was proved to be more difficult and virtually nothing is known about this aspect under experimental conditions (Harker 1973). But the entrainment of flight activity to LD 12:12 has been shown in Anopheles gambiae, Culex pipiens fatigans (Jones 1972, 1976) and in Aedes aegypti (Taylor et al. 1960). Nayar (1968) reported the entrainment of pupation rhythm in Aedes taeniorhynchus.

Data obtained from an uninterrupted 20 day period of field studies reveal that the entrained biting cycle rhythm manifests itself day after day without any marked qualitative changes.
The Effect of Ambient Light Intensity on the Biting Activity

The changes in light intensity might play a major role in defining the timings of an activity peak. The rate of change of light intensity may be the critical factor which determines the onset of crepuscular biting. The onset of biting falls within the very short period when the rate of change is reaching its maximum (Haddow et al. 1968). Since $A$. subalbatus is a crepuscular form the sudden increase (up to ca. $17 \mathrm{~lx}$ ) or decrease (down to ca. $41 \mathrm{x}$ ) in the intensity of ambient light at the time of sunrise or sunset may determine the onset of biting activity and the mid-point values coincide with the time of local sunrise and sunset.

Few experimental studies have been made with mosquitoes on the effect of rate of change of light intensity, but it has been established that the threshold control of 'swarming' in Culex pipiens fatigans is not simply one of light intensity, but requires a gradual change of intensity towards permissive range (Corbet 1966). Interestingly, the biting cycles of $A$. subalbatus (and possibly other species of mosquitoes) coincide with the steeply increasing or decreasing phases of light during dawn and dusk. Such transitions are abrupt in the tropics and remarkably precise in timing from day to day regardless of cloud cover and other conditions. Intensities of $17 \mathrm{~lx}$ and $4 \mathrm{~lx}$ at which biting commences during dawn and dusk are reminiscent of responses of plants (Buenning 1973) and insects (Chandrashekaran and Loher 1969) in temperate climates in measuring day lengths. Plants and insects apparently also exhibit threshold responses between 1-10 1x (Buenning 1971). A very important aspect, as yet improperly understood, is the possibility that crepuscular biting species of mosquitoes may have "refractory" zones built into their systems outside the biting 'gates' with reference to light. Thus a drop in daylight intensity due to inclement weather and heavy cloud-cover would not activate them to bite.

\section{The Phases of Moon and Biting Cycle}

Larger numbers of host-seeking female mosquitoes of $A$. subalbatus were collected during full moon phase than during the new moon phase. Nelson (1971) reported that the light-trap collections of Culicoides variipennis often were larger in moon light than in darker periods probably reflecting the enhanced flight activity of $C$. variipennis during the moon light. Even when temperatures were steadily decreasing, activity sharply increased with moonrise on nights near last quarter moon. Similarly Muradov (1966) found that the landing rates of $C$. schultgei and C. puncticollis were greater in moon light than darker periods. However, when Bidlingmayer (1961) sampled flying populations of C. furens with a truck trap, collections increased during moon light on some nights but decreased on others.

Miller et al. (1970) reported to the contrary that species of Anopheles and Culex were collected in larger numbers during the weeks of new moon than during those of full moon. The number of female An. subpictus collected during the full moon phases was significantly lower than during other phases of moon. An. philippinensis, An. ragus, Culex annulus, C.fuscocephalus, C. gelidus and $C$. tritaeniorhynchus did not show significant differences among the means for the first three quarters of moon. However, the collection levels on full moon nights were always lower than those of new moon. In the case of Aedes lineatopennis, Mansonia annulifera, $M$. indiana and $M$. uniformis a lunar influence was not apparent and none of these species exhibited a significant 
difference among mean numbers collected during the various lunar quarters.

In the nocturnal species of the mosquitoes (Culex spp. and Anopheles spp.) the biting - landing cycle is inhibited by the moon light whereas in the diurnal species (Aedes spp.) the moon light does not have any influence over the biting activity during the dark phase. Since Armigeres subalbatus is crepuscular in its biting habits the moon light appears to act as an 'attractant'. To this extent the responses of this mosquito to moon light may be direct and devoid of any endogenous or lunar periodic component. Further, it is evident that the intensity of the light (around twilight range) at which the maximum number is collected, is close to that of moon light intensity. The variable influence of moon light (which is in the range of $0.2-0.5 \mathrm{~lx}$ depending on latitude) on the different species of mosquitoes is obviously another adaptation aimed at temporal partitioning of available food resources.

\section{The Biting Behaviour of A. subalbatus}

The man-biting behaviour of the mosquito was of either of the exophagic or endophagic type. An estimate of the degree of endophagy and endophagy can be obtained when the relative proportions of the mosquitoes attempting to bite indoors and outdoors were compared (Krafsur 1977). It is evident from the collections made that more than $90 \%$ were biting outdoors and thus $A$. subalbatus exhibited a marked degree of exophagic behaviour. This is quite similar to the exophagic behaviour exhibited by some other spp. of mosquitoes (Krafsur 1972, 1977). However, An. pharoensis seemed ambivalent in choice of feeding sites, since $50 \%$ was attracted by man indoors and equal proportion remained outside (Krafsur 1977).

When the indoor and outdoor components of hourly manbiting of A. subalbatus were compared, it was noted that the time of biting was exactly similar in both indoor and outdoor environments as shown in the species of Anopheles (Krafsur 1977). But, McClelland $(1959,1960)$ obtained contrasting results in Aedes aegypti. He found that domestic populations of $A$. aegypti in Kenya coast show a very ill-defined biting cycle, whereas an outdoor population of the same species in Uganda has a very sharply defined cycle. Furthermore, in the latter area the time of biting by the same species found inside the huts differs by $12 \mathrm{~h}$ from biting time outside the huts. This observation, from the point of view of entrainment of biological rhythms by "Zeitgeber" in nature, is of much fascination. McClelland's observations might be hinting at a state of 'free run' (Buenning 1973), of the biting cycle.

The vertical stratification of biting activity in the study area was noticed since the total number of $A$. subalbatus collected at the ground level was higher than the mosquitoes collected at the first floor. Such vertical stratification is observed in the phlebotomine sandfly species, Lutzomyia olemca, L. panamensis and L. pessoana which were predominantly active at ground level (Chaniotis et al. 1971)

The vertical stratification of biting activity in $A$. subalbatus, is probably a response to one or more of the differences in biological and physical parameters. The occurrence of the crepuscular sandflies species was greater than the diurnal and nocturnal forms at the ground level (Chaniotis et al. 1971). Since A. subalbatus is also a crepuscular species, it occurs predominantly at ground level. The vertical stratification may also, however, indicate the powers of flight of the species being considered.

Acknowledgements. This work has benefited immensely from field and meteorological equipment which have been acquired under the "Indo-
German Project on Animal Behaviour" supported by the University Grants Commission (New Delhi). DFG, Alexander von Humboldt-Stiftung and DAAD (Bonn) and carried out jointly by the School of Biological Sciences, Madurai Kamaraj University, Madurai and the Fachbereich Biologie/Zoologie der Universitaet, Frankfurt/M., Federal Republic of Germany. We are grateful to Professor Dr. D. Neumann for critically reading through an earlier version of the manuscript and suggesting substantial improvements.

\section{References}

Barnard DR, Mulla MS (1977) Diel periodicity of blood feeding in the mosquito Culiseta inornata in the Coachella valley of southern California. Mosq News 37:669-673

Bidlingmayer WL (1961) Field activity studies of adult Culicoides furens. Ann Ent Soc Amer 54:149-156

Boorman MA (1960) Studies on the biting habits of the Mosquito Aedes (Stegomyia) aegypti. Lin., in a West Africa village. W Afr Med J 9:111-122

Buenning E (1971) Symptoms, problems and common features of circadian rhythms in plants and animals. Proc Int Symp Circadian thythmicity, Wageningen Centre for Agricultural Publishing and Documentation 11-31

Buenning E (1973) The Physiological Clock. London, The English Universities Press Ltd

Chandler JA, Highton RM, Hill MN (1975) Mosquitoes of Kano Plain, Kenya I. Results of indoor collections in irrigated and non-irrigated areas using human bait and light traps. J Med Entomol 12:504-510

Chandler JA, Highton RM, Hill MN (1976) Mosquitoes of Kano Plain, Kenya II. Results of outdoor collections in irrigated and non-irrigated areas using human and animal bait and light traps. J Med Entomol $13: 202-307$

Chandrashekaran MK, Loher W (1969) The relationships between the intensity of light pulses and the extent of phase shifts of circadian rhythms in the eclosion rate of Drosophila pseudoobscura. J Exp Zool 172:147-152

Chaniotis BN, Correa AM, Robert BT, Johnson KM (1971) Daily and seasonal man-biting activity of Phlebotomine sandflies in Panama. J Med Entomol 8:415-420

Clements AN (1963) The physiology of mosquitoes, London, Pergamon Press

Corbet PS (1966) The role of rhythms in insect behaviour. In: Insect Behaviour, Haskell (ed) R Entomol Soc Symp 13-28

Gillett JD (1969) Aedes simpsoni in Chaggalan, Tanzania. Ann Trop Med Parasit 63:147-156

Haddow AJ (1954) Studies of the biting habits of African mosquitoes. An appraisal of methods employed, with special references to the twenty-four hour catch. Bull Entomol Res 45:199-242

Haddow AJ, Casley DJL, O'Sullivan JP, Ardoin PML, Ssenkubuge Y, Kitma A (1968) Entomological studies from a high steel tower in Zika Forest, Uganda II. The biting activity of mosquitoes above the forest canopy in the hour after sunset. Trans $\mathrm{R}$ ent Soc Lond $120: 219-236$

Harker JE (1973) Circadian rhythms in Insects. In : Mills JN (ed) Biological aspects of circadian rhythms. London, Plenum Press 189-233

Jones MDR, Cubbin CM, Marsh D (1972) Light-on effects and the question of bimodality in the circadian flight activity of the mosquito Anopheles gambiae. J Exp Biol 57:347-357

Jones MDR (1976) Persistence in continuous light of a circadian rhythm in the mosquito Culex pipiens fatigans. Wied Nature Lond 261:491492

Krafsur ES (1972) Observations on the bionomics of Mansonia (Mansoniodes) uniformis (Theobald) and $M$. (M.) africana (Theobald) in Gambela, Illubabor Province, Ethiopia. Mosq News 32:73-79

Krafsur ES (1977) The bionomics and relative prevalence of Anopheles species with respect to the transmission of Plasmodium to man in Ethiopia. J Med Entomol 14:180-194

Lumsden WHR (1955) Entomological studies relating to yellow fever 
epideminology at Gede and Taveta, Kenya. Bull Entomol Res 46:149-183

McClelland GAH (1959) Observations on the mosquito, Aedes (Stegomyia) aegypti (L.) in East Africa I. The biting cycle in an outdoor population at Entebbe, Uganda. Bull Entomol Res 50:227-235

McClelland GAH (1960) Observations on the mosquito Aedes (Stegomyia) aegypti (L.) in East Africa II. The biting cycle in a domestic population on the Kenya Coast. Bull Entomol Res 50:687-696

Miller TA, Stryker RG, Wilkinson RN, Esha S (1970) The influence of moon light and other environmental factors on the abundance of certain mosquito species in light-trap collections in Thailand. $\mathrm{J}$ Med Entomol 7:555-561

Muradov SM (1966) The nocturnal activity of biting midges of the genus Culicoides (Diptera:Heleidae) in Turkmenia. Zool Zh 45:1264 1266

Nayar JK (1968) The pupation rhythm in Aedes taeniorhynchus. IV. Further studies of the Endogenous Dirunal (circadian) Rhythm of Pupation. Ann Entomol Soc Amer 61:1408-1417

Nelson RL, Bellamy RE (1971) Patterns of flight activity of Culicoides variipennis (Coquillett) (Diptera:Ceratopogonidae). J Med Entomol $8: 283-291$

Rakai IM, Naserua JD, MacNamara FN, Pillai JS (1974) Mosquitoborne infections in Fiji IV. Biting times for village mosquitoes and human filaria transmission potential of Aedes polynesiensis and Aedes pseudoscutellaris. J Med Entomol 11:588-594

Reuben R (1971) Studies on the mosquitoes of North Arcot District, Madras State, India Part 2. Biting cycles and behaviour on human and bovine baits at two villages. J Med Entomol 8:127-134

Roberts DR, Scanlon JE (1975) The ecology and behaviour of Aedes atlanticus $\mathrm{D}$. \& $\mathrm{K}$. and other species with reference to keystone virus in the Houston area, Texas, J Med Entomol 12:537-546

Saunders DS (1976) Insect Clocks, Oxford, Pergamon Press

Taylor B, Jones MDR (1969) The circadian rhythm of flight activity in the mosquito Aedes aegypti $(\mathrm{L})$ : The phase setting effects of lighton and light-off. J Exp Biol 51:59-70

Teesdale C (1965) Studies on the bionomics of Aedes aegypti (L) in the natural habitats in a coastal region of Kenya. Bull Ent Res 46:711-742

Trpis M, McClelland GAH, Gillett JD, Teesdale C, Rao TR (1973) Diel periodicity in the landing of Aedes aegypti on man. Bull Wld H1th Org 48:623 629

Trpis M, Gerberg EJ (1974) Diel periodicity in the biting activity of Aedes woodi in East Africa. Mosq News 34:443-446

Received May 27, 1980 